Vol. 11(4), pp. 141-145, 23 February, 2016

DOI: $10.5897 /$ ERR2015.2532

Article Number: FBA5FF057170

ISSN 1990-3839

Copyright (c) 2016

Educational Research and Reviews

Author(s) retain the copyright of this artic le

http://www.academic joumals.org/ERR

\title{
The correlation of multiple intelligences for the achievements of secondary students
}

\author{
Yaghoob Raissi Ahvan* and Hossein Zainali Pour \\ Department of Psychology, Hormozgan University, Iran. \\ Received 22 November, 2015; Accepted 05 January, 2016
}

\begin{abstract}
The present study attempts to investigate the relationship between the multiple intelligences and the academic performance achievement levels of high school students based on Gardner's multiple intelligences theory. This was a descriptive correlation study. To accomplish this purpose, 270 students of high school of Bandar Abbas selected by clustering random sampling, and all of them filled the Gardner's multiple intelligences questionnaire. For analysis of collected data, descriptive statistics including Mean, Standard Deviation, Pearson coefficient correlation and regression were used. Findings of this study revealed that moderate inter-correlation exists between verbal-linguistic and visual-spatial intelligences and academic performance achievement $(p<05)$. Multiple intelligences such as logical-mathematical, visual-spatial, verbal-linguistic, intrapersonal, bodily-kinesthetic, interpersonal and naturalistic have a significant positive relationship with academic performance achievement of students $(p<05)$. It became clear that multiple intelligences like visual-spatial, verbal-linguistic and interpersonal statistically significant and were able to predict academic performance achievement $(p<05)$, whereas musical intelligence was a tunable negative predicator for academic performance achievement of students.
\end{abstract}

Key words: Gardner's multiple intelligences, academic performance achievement, students.

\section{INTRODUCTION}

In today's world, rapid and wide developments in science, technology, communication and emergence of new views about social, political, economic, and cultural issues bring about fundamental changes in educational systems and teaching methods (Otaghsara, 2014).

Allah has given man intelligence, which is the cause of superiority among all other creatures. Intelligence is of paramount importance in a person's life. Therefore the topic of intelligence is of substantial curiosity and interest to researchers and lay people (Mackintosh, 1998). General, interpersonal, fluid, and crystalized as well as many other types of intelligence have been discovered.

For many years, educators have implemented traditional teaching methods in the classroom that have tended to classify learners as a homogeneous group where teachers use the executive approach to transmit knowledge to all the students with a similar set of teaching methods (Sulaiman et al., 2011). With the

*Comesponding author. E-mail: yrahvan1343@gmail.com

Authors agree that this article remain permanently open access under the terms of the Creative Commons Attribution Lic ense 4.0 Intemational License 
traditional teaching approach, teachers struggle to find ways to reach the diversity of individual learning styles and needs. Learning styles is connected to individual characteristics and preferences, which reflect how a person perceives and interacts with the environment (Sulaiman et al., 2011).

According to Gardner, there are biological and cultural bases for multiple intelligences. Accepting Gardner's Theory of Multiple Intelligences has several implications for teachers in terms of classroom instruction. The theory states that all seven intelligences are needed to productively function in society. Since all children do not learn in the same way, they cannot be assessed in the same way. Therefore, it is important that an educator creates an "intelligence profiles" for each student. Knowing how each student learns will allow the teacher to properly assess the child's progress (Lazear, 1992).

In the context of education and students' achievement, multiple intelligences are especially powerful because they help parents and teachers understand education holistically. Gardner (1994) says multiple intelligences persuade parents and teachers to examine their own ideas and assumptions about achievement and consider various teaching approaches. This suggestion provides a powerful lens to analyze multiple intelligences in the context of secondary student performance.

Gardner stretches the word intelligence beyond its customary application in psychology (Gardner and Hatch, 1989), and defines it as a bio-psychological ability of processing information, that can be activated to handle a problem properly, and creating such a product that is valued in a cultural setting. He developed a theory of multiple intelligences and asserted that each individual has not only one general intelligence, but multiple intelligences. Multiple intelligences theory promotes the idea that every individual is capable of learning through the range of different intelligences. He initially proposed six intelligences, but then added two additional intelligences (Gardner, 1999). These intelligences are: logical-mathematical, verbal-linguistic, visual-spatial, intrapersonal, bodily-kinesthetic, interpersonal, naturalistic and music intelligences.

Gardner asserted that individual differences reflect multiple intelligences of human beings; and through these intelligences an individual tries to understand the world, these are personal strengths through which a person comprehends the world (Arnold and Fonseca, 2004). What the Multiple intelligences theory offers is not only significant from a theoretical perspective, but also has important practical implications for teaching practice. Teachers should consider various multiple intelligences of the students during their teaching; and should persuade the students to use their different intelligences in their learning (Gen, 2000), as Larsen-Freeman(2000) suggested improving quality of teaching and learning, both teacher and learner should take into account different multiple intelligences. Regarding their career, learners' multidimensionality should be celebrated and all intellectual abilities may be enhanced (Cohen, 2003).

Gardner (2006) argued that due to the multiple intelligences individuals are truly human being. Each has a unique profile of intelligences of varying strengths. Although no one intelligence was considered to be superior to other types, according to Gardner (2003) all intelligence are required for an individual, in order to participate, act purposefully and creatively in the society.

In order to be successful in educating all students, teachers should be aware of the students' individual differences; individual learning styles and multiple intelligence profiles. In schools logical and linguistic intelligences are emphasized in teaching. Students who are more developed in other intelligence dimensions are often ignored. Identifying and knowing students' intelligence profile is important and has implications for instruction (Shalk, 2002). For example, if a student has limited success with verbal and mathematical intelligences, more success may be achieved by using some of the other intelligences (Oddleifson, 1994). A Multiple intelligences approach offers suggestions for providing a more reasonable and practical approach to schooling (Eisner, 1994). Furthermore, since intelligence strengths and weaknesses are not static, they may be improved with different educational experiences. For this reason, multiple intelligences theory approach supports continuous assessment of intelligences starting at an early age (Shalk, 2002).

Some researchers have found in their studies, intelligence as a cause of academic performance (Habibollah et al., 2008). A close connection by some of the psychologists between intelligence and academic achievement was discovered. Some say that there is cause and effect relationship between the two variables. According to Laidra et al. (2007) academic achievement of the students is reliant on their cognitive abilities through all grade levels.

Multiple intelligence theory is assuming an important place in the recognition of the diversity of ways that learners approach the curriculum; it helps teachers and learners to successfully programme for individualized instruction. Consequently, many researchers stress the importance of identifying the profiles of the learners and empowering them with recognition of their intelligences, in order to enhance and develop learning (Gurbuz and Gurbuz, 2010; Natasa 2010; Netoa et al., 2008; Wu and Alrabah, 2009). Thus, it seems necessary to recognize students' intelligences in order to consider them, when designing for the teaching and learning process to enhance their learning performance.

Several studies suggest multiple intelligence-based instruction increases students' achievement. The following research indicates a number of positive outcomes including increased students' confidence, intrinsic 
Table 1. Self-estimated multiple intelligences of high school students $(N=270)$.

\begin{tabular}{lcc}
\hline \multicolumn{2}{l}{ Gardner's multiple intelligences } & \multirow{2}{*}{ Standard deviation } \\
\cline { 1 - 2 } Multiple intelligences & Mean & Ind \\
\cline { 1 - 2 } Interpersonal & $3 / 52$ &.$/ 68$ \\
Logical- mathematical & $3 / 42$ &.$/ 76$ \\
Visual-spatial & $3 / 52$ &.$/ 75$ \\
intrapersonal & $3 / 51$ &.$/ 61$ \\
naturalistic & $3 / 41$ &.$/ 80$ \\
Verbal-linguistic & $3 / 32$ &.$/ 98$ \\
Bodily-kinesthetic & $3 / 05$ &.$/ 70$ \\
Musical & $2 / 02$ &.$/ 80$ \\
\hline
\end{tabular}

motivation, engagement, and performance on standardized tests (Campbell and Campbell, 1999; Kornhaber et al., 2004).

Numerous research studies have explored the effects of different variables on students' academic performance achievement. Little attention was paid in Iran especially under-developing city like Bandar Abbas to the interrelationship of multiple intelligences and with academic performance achievement. This current study explored this relationship using public high school students as participants from Bandar Abbas, the Southern City of Iran.

\section{METHODS}

This was a descriptive correlation study. Participants of this study were 270 students randomly selected from among public and private high schools students in Bandar Abbas. Douglas and Harm's questionnaire of multiple intelligences consisting of 80 statements was used as data collection instrument. This inventory is a standardized inventory, describing Gardner's eight multiple intelligences. Each intelligence was measured through ten statements. The composite inventory was translated into Persian with the help of research language expert in order to make it understandable for students. In order to find out the reliability, the inventory was distributed among 182 public high school students of Tehran, as a pilot test. The Cronbach's Alpha Value found out for different intelligences, verbal-linguistic . 176, logical-mathematical .$/ 71$, visual-spatial ./74, bodily-kinesthetic ./63, musical ./76, intrapersonal ./60, interpersonal ./70, naturalistic ./84 respectively, the Cronbach's Alfa Value for the whole inventory was ./81 .

\section{RESULTS}

The research hypotheses of this study are:

1-There is a statistically significant relationship between the multiple intelligences and the academic performance achievement levels of high school students of Bandar Abbas.
2- The multiple intelligences act as the predicator of the academic performance achievement levels of high school students of Bandar Abbas.

Analysis and interpretation of data were done in this section. The statistical values were calculated carefully. Mean, Standard Deviation, Pearson Coefficient Correlation and Regression were used as statistical tests. The data are arranged in Tables 1-3.

Different levels of correlation between multiple intelligences were found. The Coefficient Correlation between self-estimated verbal-linguistic and visual-spatial intelligence is .466, indicated moderate correlations between the multiple intelligences. The Coefficient Correlation between self-estimated bodily-kinesthetic and logical-mathematical intelligence is .39, naturalistic and intrapersonal is .38, mathematical-logical and visualspatial intelligence is .377 , revealed low moderate correlations. Musical and logical-mathematical intelligence is .08 showed weak but negligible correlations (Table 1 ).

Moderate correlation ( $r=.38, r=.36)$ exists between self- estimated verbal-linguistic, visual-spatial intelligence and academic performance achievement. Significant but weak correlation $(r=.23, r=.19, r=.17, r=.15, r=.13)$ exists between logical-mathematical, interpersonal, intrapersonal, naturalistic, and bodily-kinesthetic intelligences and academic performance achievement, and no correlation exists between musical intelligence and academic achievement at.05 level of significance (Table 2).

The standardized beta coefficient gives a measure of the contribution of each variable to the model. A large value indicates that a unit change in this predicator (independent) variable has a large effect on the criterion (dependent) variable. The $T-$ Value and $P$ _Value give a rough indication of the impact of each predicator variable; a big absolute $T_{-}$Value and a small $P_{-}$Value suggest that a predicator variable is having a large impact on the criterion variable.

Based on the data presented in Table 3 , it can be concluded that verbal-linguistic and visual-spatial intelligences were the predicators of multiple intelligences and academic performance achievement $(p<01)$ among Bandar Abbas high school students which yielded multiple regression coefficient ( beta ) of ./29 and ./27, respectively. Other intelligences did not predicate multiple intelligences and academic performance achievement among the students of Bandar Abbas ( $p>/ 05)$, especially musical intelligence was a tunable negative predicator for academic performance achievement of students which yielded multiple regression coefficient ( beta ) of -./25 .

\section{DISCUSSION}

The findings of the study confirmed Gardner assertion, 
Table 2. Coefficient correlation between multiple intelligences and academic performance achievement.

\begin{tabular}{lcc}
\hline \multicolumn{2}{c}{ Gardner's Multiple Intelligences } & \multirow{2}{*}{ significance } \\
\cline { 1 - 2 } Multiple intelligences & Coefficient correlation & \\
\hline Visual-spatial &.$/ 36$ &.$/ 01$ \\
Verbal-linguistic./38 &.$/ 38$ &.$/ 01$ \\
Logical-mathematical &..$/ 23$ &.$/ 01$ \\
Intrapersonal &.$/ 19$ &.$/ 01$ \\
Interpersonal &.$/ 17$ &.$/ 05$ \\
Bodily-kinesthetic &.$/ 13$ &.$/ 01$ \\
naturalistic &.$/ 15$ &.$/ 05$ \\
musical &.$/ 3$ &.$/ 01$ \\
\hline
\end{tabular}

Correlation is significant $p<.05$.

Table 3. Multiple regression predicting the relationship between multiple intelligences and academic performance achievement of students.

\begin{tabular}{lccccc}
\hline \multirow{2}{*}{ Model } & $\mathbf{t}$ & $\boldsymbol{\beta}$ SStandardized & \multicolumn{2}{c}{ Unstandardized coefficient } & \multirow{2}{*}{ Significance } \\
\cline { 1 - 3 } & & & $1 / 09$ & $4 / 44$ &.$/ 001$ \\
\cline { 1 - 1 } Constant & $4 / 97$ & &.$/ 04$ &.$/ 04$ &.$/ 30$ \\
Logical-mathematical & $1 / 03$ &.$/ 09$ &.$/ 06$ &.$/ 14$ &.$/ 01$ \\
Visual-spatial & $2 / 30$ &.$/ 27$ &.$/ 03$ &.$/ 12$ &.$/ 001$ \\
Verbal-linguistic & $3 / 62$ &.$/ 29$ &.$/ 08$ &.$/ 09$ &.$/ 44$ \\
naturalistic &.$- / 75$ &.$- / 05$ &.$/ 07$ &.$/ 06$ &.$/ 84$ \\
intrapersonal &.$/ 19$ &.$/ 04$ &.$/ 05$ &.$/ 11$ &.$/ 005$ \\
interpersonal & $2 / 00$ &.$/ 25$ &.$/ 02$ &.$/ 03$ &.$/ 19$ \\
Bodily-kinesthetic & $1 / 40$ &.$/ 14$ &.$/ 06$ &.$- / 12$ &.$/ 01$ \\
musical & $-2 / 1$ &.$- / 25$ & & & \\
\hline
\end{tabular}

that every person possesses multiple intelligences. Results of the study also align with the previous research indicated that every individual has different types of intelligence with different levels of each.

The study provided evidence that the verbal-linguistic intelligence is the student's most frequent intelligence and the musical intelligence is the students' least frequent intelligence. This could be due to the opportunities, environment available for the nourishment of an intelligence; it is quite possible that verbal-linguistic intelligence might have developed due to the environment available to it, and musical and other intelligences might have remained underdeveloped or moderately developed because and encouraging environment was not available to them. The southern cities of Iran are underdeveloped and the students have limited opportunity to enhance their multiple intelligences. This may be due to the practice and non-application of the theory of multiple intelligences in teaching learning process. Neither pedagogical strategies are planned nor students are encouraged to use various intelligences in their learning; therefore an unbalanced development of multiple intelligences might have occurred. Basic facilities like computer, net, multimedia are hardly available in schools teachers and students have fewer opportunities to develop their multiple intelligences. Another reason could be that different cultures value different intelligences, especially in Iran where verbal-linguistic intelligence is highly valued and musical intelligence is discouraged. This may explain the relatively high level of verballinguistic learning and the lower levels of musical and moderate level of other dimensions.

The researcher also found that the multiple intelligences are interconnected. Here too results of the study confirmed the claim of Gardner. He says that although multiple intelligences are separate units but they support each other whenever a job is performed.

The researcher also found a moderate association 
between verbal-linguistic, visual-spatial intelligence and academic achievement. Result of the study is in consonance with Haji et al. (2004): he found in his study a significant positive correlation between perceived verbal-linguistic, visual-spatial intelligences and academic achievement of the students. Overall, there is a significant positive correlation between perceived verbal-linguistic, bodily-kinesthetic, logical-mathematical, musical intelligence and academic achievement of the students and it shows moderate correlation.

This result is also aligned with the results of Deary et al. (2007), who discovered a positive relationship between verbal-linguistic intelligence and academic achievement. Furnham et al. (2002) found in their research, that the respondents considered that verbal, spatial and logical intelligences exemplify true intelligence. The hypothesis no 2 developed by the above researchers in their study, which states that verbal, spatial and logical intelligences are the best predictors of academic performance achievement also supported by the results of this study. It can be also said that results of the study is reflection of our traditional teaching, in the schools of southern city of Iran, Bandar Abbas which focus on verbal-linguistic and visual-spatial dimensions only.

\section{Conclusion}

The verbal-linguistic intelligence is the students' most dominant and the musical intelligence is the students' least dominant intelligences. The evidence proved that the multiple intelligences are interconnected and support each other during performance. The verbal-linguistic and visual-spatial intelligences are moderately, interpersonal, intrapersonal, naturalistic, and bodily-kinesthetic intelligences are weakly correlated and musical intelligence is not correlated to academic achievement. Identifying the multiple intelligences of high school students, the differences according to the academic performance achievement will contribute an awareness to the selfknowledge and abilities of the students as well as to develop suggestions for programs to enhance their academic performance achievement and to be a reference for further studies.

\section{Application}

Multiple intelligences need to be incorporated in teaching, learning process, formally in Iran, especially in schools of southern city like Bandar Abbas; so the students may have the opportunities to develop all intelligences not just verbal-linguistic intelligence. Teachers should create such an environment, which is favorable for the development of all the intelligences, keeping in view individual differences of the students.

\section{RECOMMENDATION}

Additional research is needed. For example, experimental studies may be conducted on students of different ages in different localities in order to compare the results and find out the actual correlation between multiple intelligences and academic performance achievement.

\section{Conflict of Interests}

The authors have not declared any conflicts of interest.

\section{REFERENCES}

Arnold J, Fonseca CM (2004). Multiple intelligence theory and foreign language learning: A brain-based perspective. Int. J. English Stud. 4(1):119-136.

Campbell L, Campbell B (1999). Multiple intelligences and student achievement: Success stories from six schools. Alexandria, VA: Association for Supervision and Curriculum Development.

Cohen AD (2003). The learner's side of foreign language learning; where do styles, strategies, and tasks meet? Int. Res. Appl. Linguistic, 41:279-291.

Eisner E (1994). The educational imagination: On the design and evaluation of school programs (3rd ed.). New York, NY: Macmillan.

Gardner H (2003). Multiple intelligences after twenty years. American Educational Research Association, Chicago, Illinois, 21.

Gardner H (2006). Multiple intelligences new horizons. New York: Basic Books.

Gardner H, Hatch T (1989). Multiple intelligences go to school: Educational implications of the theory of multiple intelligences. Educ. Res. 18(8):4-9.

Gardner H (1994). The stories of the right hemisphere. In W. D. Spaulding (Ed.), Integrative views of motivation, cognition and emotion, Vol. 41 of The Nebraska Symposium on Motivation (pp. 5769). Lincoln: University of Nebraska Press.

Gardner H (1999a) Intelligence reframed: Multiple intelligences for the 21st century. New York: Basic Books.

Gen R (2000). Technology and multiple intelligences: The praxis of learning intelligences. Education at a Distance, 14(4). Retrieved February 10, 2009, from http://www.usdla.org/html/journal/MAY00_Issue/st ory 02.htm

Gurbuz, Gurbuz (2010). Determination of preschool children's dominant and non-dominant types of intelligences with regard to "The Theory of Multiple Intelligences": A Qualitative Evaluation. E - Journal of New World Sciences Academy, 5(2):456-470.

Habibollah N, Abdullah R, Tengku Aizan H (2008). Male versus female intelligence among undergraduate students. Does gender matter? Asian J. Scientific Res. 1(5):539-543

Haji Hosseini, Nejhad Gh, Baleghi Zadeh S (2004). The comparison of teaching method on Gardner's multiple intelligences.Season letter of mathematic training, 20:1-19.

Kornhaber ML, Fierros E, Veenema S (2004). Multiple Intelligences: Best ideas from theory and practice. Needham Heights, MA: Allyn \& Bacon.

Laidra K, Pullmann H, Allik J (2007). Personality and intelligence as predictors of academic achievement: A cross-sectional study from elementary to secondary school. Personality and Individual Differences, 42(3):441-451.

Larsen-Freeman D (2000). Techniques and principles in language teaching. (2nd ed.). Oxford: Oxford University Press.

Oddleifson E (1994). What do we want our schools to do? Phi Delta Kappan. 75(6):446-453.

Sulaiman T, Hassan A, Yi H (2011). An analysis of teaching styles in primary and secondary school teachers based on the theory of multiple intelligences. J. Social Sci. 7(3):428-435. 